\title{
A SELETIVIDADE DO SISTEMA PENAL E A QUESTÃO DE GÊNERO COMO COLABORADORAS DA REINCIDÊNCIA FEMININA
}

\author{
Shirley Silveira Andrade \\ Mestre em Direito pela Universidade Federal de Pernambuco- Instituto superior de Olinda. \\ e-mail: silveiran@hotmail.com
}

\section{Giselle da Conceição Freitas}

Aluna de graduação da Universidade Salgado de Oliveira.

e-mail: giselle_freitas4@hotmail.com

RESUMO: Este trabalho é resultado de uma pesquisa que está sendo realizada desde junho de 2004 na Colônia Penal Feminina do Recife - Bom Pastor, no Estado de Pernambuco. Tem como objeto as causas da reincidência feminina das internas que cumprem pena nesta instituição de junho a dezembro de 2004. Utilizando-se, dentre outras, das categorias de Michel Foucault, partimos das hipóteses de que as causas de reincidência criminal do nosso sujeito se dão pelo fato de o sistema penal ser seletivo, já que o grupo que está na prisão é o pobre, e de que a atitude dessas mulheres é influenciada pela relação de poder que há entre elas e seus companheiros. Trabalhamos as categorias seletividade e gênero. A metodologia utilizada se biparte. Na primeira fase, fizemos um levantamento documental analisando os prontuários das internas. Na segunda fase, iremos entrevistá-las. Os prontuários demonstram que o grau de escolaridade das detentas é relativamente baixo $-41,94 \%$ delas estudaram entre a $1^{\underline{a}}$ e $4^{\underline{a}}$ séries do ensino básico - e, ainda, que sua situação econômica é esmagadoramente pobre - 80,65\%. De acordo com os resultados obtidos, confirmamos a primeira hipótese, haja vista a população carcerária da Colônia Penal do Recife - Bom Pastor ser composta quase que totalmente pela classe menos favorecida. Quanto à segunda hipótese, será verificada junto com as entrevistas, mas já há alguns dados nos prontuários que revelam a relação entre a reincidência criminal feminina e seus companheiros.

PALAVRAS-CHAVE: Reincidência; Gênero; Seletividade. 


\section{RELAÇÃo ENTRE SELETIVIDADE E GÊNERO NA REINCIDÊNCIA CRIMINAL}

Na primeira página do livro 'Vigiar e Punir', de Michel Foucault, é exposto um ritual de punição do século XVIII. ${ }^{1}$ Todos os passos demonstrados são considerados, hoje em dia, como uma forma cruel e inadequada de aplicar pena. Rompendo com a base de idéias que fundamentava essa estrutura penal, surgiram alguns autores que basearam a função de punir na teoria contratualista.

O primeiro deles que se tem notícia é Cesare Beccaria. Este autor afirmou que, no início, os homens eram independentes e isolados. Ao se reunirem necessitaram abdicar de parte de sua liberdade para poderem conviver. A soma dessas abdicações, sacrifícios ao bem geral, originaria aquele que seria encarregado pelas leis como depositário dessas liberdades - o Estado. Contudo, não bastaria apenas abdicar dessa liberdade em face da soberania da nação, mas protegê-la contra as usurpações de cada particular. Seriam necessários meios sensíveis e poderosos para deter os infratores: as punições aplicadas pelo Estado. ${ }^{2}$ Dentre elas, Beccaria se refere à prisão. Ao analisá-la, faz críticas veementes a sua característica de suplício ao invés de ser um meio de deter o acusado. ${ }^{3}$

Essas idéias inauguraram o discurso que se tem da prisão como um instrumento que visa privar o sujeito de sua liberdade vigiada para mantê-lo encarcerado, a fim de que o mesmo se arrependa do delito praticado e dessa forma regenere-se, estando apto para conviver novamente em sociedade. Foi com esse objetivo a previsão do artigo $1^{\circ}$ da lei de Execuções Penais(LEP), Lei 7210 de 11 de julho de 1984: "Art 1-- A execução penal tem por objetivo efetivar as disposições da sentença ou decisão criminal a proporcionar condições para a harmônica integração social do condenado e do internado". (grifo nosso)

Se os objetivos da prisão, quanto ao discurso, mudaram desde o século XIX, isso não tem ocorrido na mesma proporção de sua aplicação. O Departamento

\footnotetext{
${ }^{1}$ Foucault descreve como um rapaz condenado por matar seu pai recebia a pena de morte. Primeiro vinham os suplícios, ferimentos muito dolorosos. Depois o rapaz foi amarrado a quatro cavalos para ser dividido em quatro partes.

${ }^{2}$ Beccaria, Cesare. Dos delitos e das penas. São Paulo: Martin Claret, 2003. p. 25.

${ }^{3}$ Beccaria, Cesare. Dos delitos e das penas. São Paulo: Martin Claret, 2003. p. 34-35.

${ }^{4}$ Essa legislação surgiu imbuída do espírito internacional de humanismo quanto a execução das penas e seus tipos. Prevê vários direitos dos presos e tem como objetivo a sua ressocialização.
} 
Penitenciário Nacional (DEPEN) declarou que, no Brasil, a taxa de reincidência, pessoas que voltam a cometer crimes, é de $85 \%{ }^{5}$ Esse alto índice nos motivou a questionar que se já há uma legislação consubstanciando o princípio moderno da ressocialização por que ela não estaria ocorrendo.

Além disso, haveria uma questão pouco explorada pelos estudos no que se refere a repetição de delitos: o gênero. A reincidência feminina se equipara à masculina? A criminalidade masculina está equiparada à feminina? Como não podemos responder essa última pergunta, no momento, objetivamos continuar com o projeto para tentar respondê-las, limitamo-nos ao estudo da reincidência feminina, a tentar responder a primeira pergunta. Para tanto, escolhemos como nosso sujeito as mulheres reincidentes do presídio feminino Bom Pastor, localizado na cidade do Recife.

Segundo dados do SUSIPE, este presídio, apesar de ter uma capacidade de lotação de 85 Presas, possui 183. 71 com sentença condenatória em regime fechado, 112 sendo processadas e 2 em regime semi-aberto. Diante desse universo, escolhemos dentre as condenadas, as reincidentes, que já foram condenadas por algum crime antes de estar cumprindo pena atualmente, de junho a dezembro de 2004, critério que enxuga o sujeito. Nosso objeto de estudo está delimitado da seguinte forma: quais as causas da reincidência feminina das internas que estão cumprindo pena de junho a dezembro de 2004 no presídio Bom Pastor?

Com a percentagem de $85 \%$ de reincidência, podemos observar que o que a LEP afirma em seu artigo, não está sendo eficazmente efetivado. Portanto, quais seriam as causas dessa reincidência? Quais as causas da reincidência feminina das internas que estão cumprindo pena de junho a dezembro de 2004 no presídio Bom Pastor? Tendo como marco teórico Michel Foucault, partimos de uma primeira hipótese defendendo que o sistema penal é seletivo, pois o código penal é infringido a todo momento por todos os grupos sociais, mas o grupo que está na prisão é o pobre. As pessoas que passam pela prisão ficam estigmatizadas e têm dificuldade de se inserirem socialmente. Arrumar empregos, amigos, e por essas dificuldades voltam a delinqüir.

No entanto, é importante salientar que o sistema penal tem sido criticado com veemência. Vários estudos e até mesmo a sociedade, de um modo geral, dão

\footnotetext{
${ }^{5}$ Segundo o Departamento Penitenciário Nacional (DEPEN), em Fevereiro de 2002.
} 
conta que o discurso do sistema não vem sendo cumprido; ou seja, as práticas criminosas continuam; os indivíduos não se regeneram e o que é pior não conseguem inserir-se novamente no meio social.

Essa dificuldade de se "readaptar" gera a possibilidade de reincidir no crime, pois o indivíduo sem perspectiva, inclusive de trabalho, acredita não se encaixar na convivência social. É por isso que o sistema penal é seletivo, por ter uma predileção para punir os marginalizados e pobres, figuras que não têm muitas chances na sociedade.

Além dessa primeira hipótese que denominamos de seletividade, partimos de uma segunda que é o que estamos chamando de questão de gênero. Essa discussão foi suscitada já em trabalho anterior. Na verdade, pesquisa já foi realizada revelando que uma das causas da criminalidade feminina é a influência que os companheiros das mulheres possuem sobre suas vidas. Pesquisa realizada por Shirley Andrade revelou que os maridos, namorados e companheiros envolvem as mulheres na criminalidade. ${ }^{6}$ Diante disso, percebemos a importância de estudar a reincidência feminina incluindo a categoria gênero. Não apenas analisando a repetição dos delitos pela estigmatização social do ponto de vista econômico, mas também pelo papel que é imposto a mulher em nossa sociedade. As categorias colocadas nas hipóteses serão trabalhadas conceitualmente no próximo capitulo.

A metodologia esteve fundamentalmente ligada a análise dos prontuários das reincidentes, na primeira fase, o que representa $10 \%$ da população carcerária da Colônia, que até o momento da pesquisa abrigava 310 mulheres. Todavia, todos os prontuários das reincidentes foram analisados. Fez-se uma leitura minuciosa dos prontuários de cada uma delas, tendo o cuidado de sempre identificar se estavam dentro do conceito de reincidência adotado, considerando então como reincidente toda a mulher que já cumpriu alguma pena anteriormente e foi recolhida à prisão para cumprimento de nova pena ${ }^{7}$, independente do delito anterior e da pena anterior. Quanto à entrada no presídio, a mesma necessitou de alguns cuidados especiais. Primeiro tentou-se uma conversa com a diretora da colônia, o que só foi possível após três tentativas. Depois de uma conversa informal, nos direcionaram para o

\footnotetext{
${ }^{6}$ ANDRADE, Shirley Silveira. Tempo de prisão é também tempo de cidadania? Programa Institucional de Bolsas de Iniciação científica, CNPq\ UFS. Universidade Federal de Sergipe, Aracaju, 1997. p. 14.

${ }^{7}$ ADORNO, Sérgio. Prisão sob a ótica de seus protagonistas. Itinerário de uma pesquisa. Tempo social; Rev. Social. USP, S. Paulo, 1991. p. 22.
} 
setor jurídico, onde encontravam-se os prontuários das presas. As pessoas que trabalhavam nesse setor pareceram inicialmente intimidadas com nossa presença. Porém o desconforto, a medida que nos tornávamos mais assíduas para coleta de dados, diminuiu. O mais interessante, talvez, de ter trabalhado nesse setor, foi a possibilidade de observar de perto toda a movimentação da colônia, pois tudo acontecia nesse setor. A chegada das presas, ou qualquer solicitação também era feita lá. Observadas todas as impressões iniciais e constatando o fato de que as presas mais instruídas exerciam função no setor de administração, pediu-se autorização para manusear os prontuários e dar início ao trabalho.

Nos prontuários continham todos os dados de identificação das presidiárias, local onde residiam, grau de escolaridade, profissão, bem como os dados referentes aos crimes e suas respectivas penas. Continham também informações com relação aos comportamentos no presídio, às possíveis infrações disciplinares, à contagem de estudo e trabalho para efeitos de remição de pena. Após essa verificação, foram registrados todos esses dados disponíveis, por um período de três meses, os quais foram de suma importância para a confirmação da seletividade do sistema.

Estamos iniciando uma nova fase através de entrevistas semi-estruturadas, com um roteiro básico, inicialmente devendo ater-se na história da presa, e num segundo momento, vão ser relacionadas às condições de vida no presídio. Portanto, trataremos de seu cotidiano anterior à prisão, para se observar tanto seu contexto de classe social como sua identidade. E o cotidiano durante a primeira e segunda prisão, para observarmos sua seletividade.

\section{A IDENTIDADE DA REINCIDENTE}

Foucault defende que, desde o seu nascimento, a prisão já possuía criticas que denunciavam seu fracasso quanto ao objetivo ressocializador. Ela não estaria diminuindo as taxas de criminalidade, ao contrário, elas aumentavam a cada momento. Além do mais, constatou-se logo, que a detenção provocava a reincidência, onde o preso era condenado, privando-se sua liberdade, e quando voltava para a sociedade estava tão marcado pelos efeitos da prisão, que a única alternativa era voltar a delinqüir ${ }^{8}$.

${ }^{8}$ FOCAULT, Michel. Vigiar e punir: Nascimento da prisão; Tradução de Raquel Ramalhete. Petrópolis, Vozes 1987.p.149 
É nesse contexto que Focault afirma que a prisão fabrica delinqüentes, e que este fato se dá pelo próprio funcionamento da instituição, vai ainda mais além, pois diz que a mesma atinge a um grupo determinado, tendo em vista que a maioria da população carcerária é composta por negros, pobres e marginalizados o que torna o sistema penal seletivo em relação aos indivíduos que pune. ${ }^{9}$ Com a coleta de dados documentais pudemos confirmar essa hipótese. O sistema penal é seletivo.

Os percentuais contabilizados resultaram da análise dos prontuários de 31 mulheres reincidentes, conforme conceito descrito acima, correspondendo a 10\% da população carcerária da Colônia Penal, que até então abrigava 310 mulheres, entre processadas e condenadas. Os dados mostram que o grau de escolaridade e a situação econômica das mulheres são de características de grupos excluídos. $41.94 \%$ dessas mulheres estudaram entre a $1^{\underline{a}}$ e $4^{\underline{a}}$ séries do ensino fundamental $1,{ }^{10}$ ficando grande percentual restante com o ensino fundamental II. A situação econômica das mesmas é esmagadoramente pobre $80,65 \%$. O sistema penal seleciona.
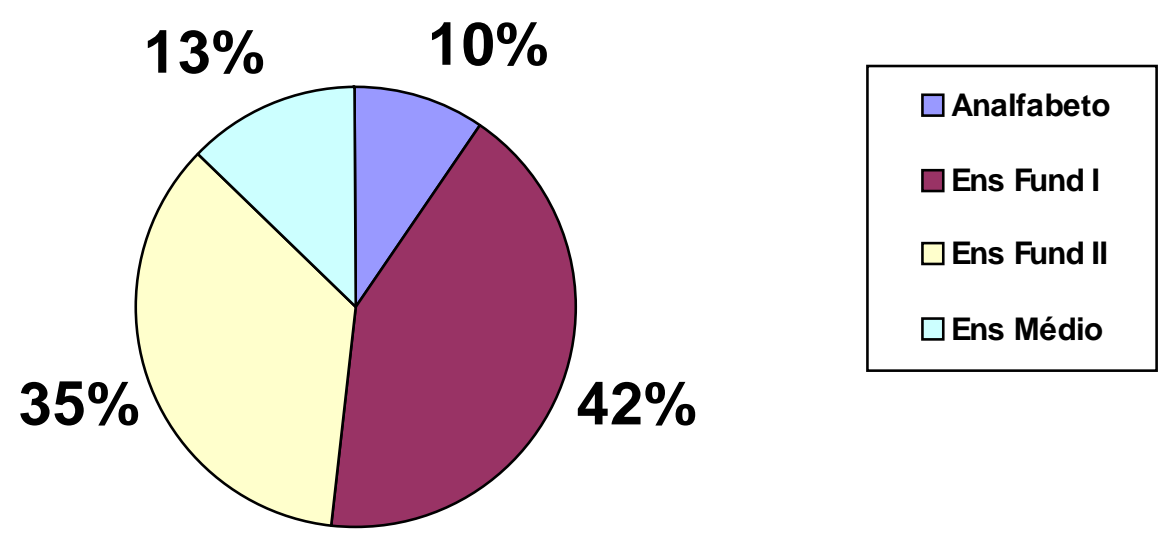

Figura 1. Grau de escolaridade das detentas reincidentes da Colônia Penal do Bom Pastor - PE.

${ }^{9}$ FOCAULT, Michel. Vigiar e punir: Nascimento da prisão; Tradução de Raquel Ramalhete. Petrópolis, Vozes 1987.p.160.

${ }^{10}$ Ensino Fundamental I: de $1^{\underline{a}}$ a $4^{\underline{a}}$ séries; Ensino Fundamental II: $5^{\underline{a}}$ a $8^{\underline{a}}$ séries 


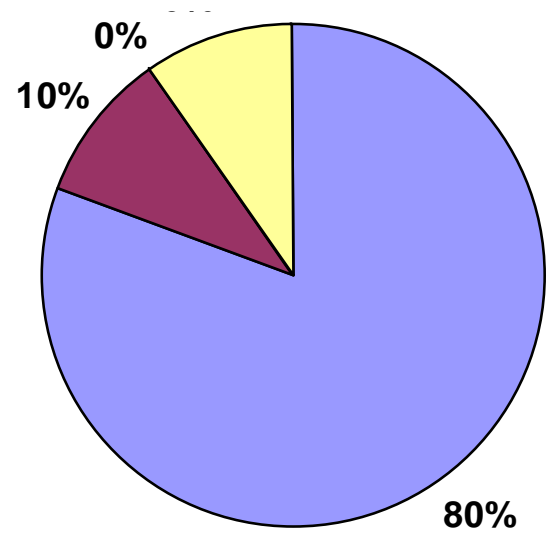

\begin{tabular}{|l|}
$\square$ Pobre \\
$\square$ Razoável \\
$\square$ Classe Média \\
$\square$ Não Inf
\end{tabular}

Figura 2. Condição econômica das detentas reincidentes da Colônia Penal do Bom Pastor - PE ${ }^{11}$.

Foucault defende que a forma de poder moderno é a do poder disciplinar, o poder de adestrar através das instituições. Um poder invisível que domina os corpos, para retirar deles cada vez mais e melhor. Um poder que tem como objetivo tornar os corpos dóceis e úteis. Essa operação seria realizada através de três mecanismos. A vigilância hierárquica, aonde o poder seria implementado pelo simples olhar, implicando modificações nas arquiteturas dos ambientes para facilitar essa fiscalização. A sanção normalizadora teria como função individualizar condutas, estabelecendo quais as pessoas que se desviam das regras para serem qualificadas como normais e anormais e, por fim, o exame, que documenta essa individualização. ${ }^{12} \mathrm{O}$ sistema punitivo pertenceria a essa lógica.

Para o francês, a penalidade serve para demarcar, selecionar certos grupos, pois a disciplina dos presídios traz consigo uma maneira específica de punir. ${ }^{13} \mathrm{O}$ que pertence à penalidade disciplinar das prisões é a inobservância, tudo que está inadequado à regra, os desvios. Segundo ele, a penalidade que atravessa todos os pontos e controla todos os instantes das infrações disciplinares compara, diferencia, hierarquiza, homogeneíza, exclui. ${ }^{14}$ Seleciona.

${ }^{11}$ Os valores de todos os percentuais estão arredondados.

12 FOUCAULT, Michel. Vigiar e punir: história da violência nas prisões. Tradução de Ligia M. Ponde Vassallo. 12. ed., Petrepolis: Vozes, 1987. p. 176.

${ }^{13}$ FOCAULT, Michel. Vigiar e punir: Nascimento da prisão; Tradução de Raquel Ramalhete. Petrópolis, Vozes 1987. p.149.

${ }^{14}$ FOCAULT, Michel. Vigiar e punir: Nascimento da prisão; Tradução de Raquel Ramalhete. Petrópolis, Vozes 1987. p. 153. 
Com os resultados obtidos, está se constatando a seletividade do sistema defendida por Foucault. Haja vista as reincidentes da Colônia Penal do RecifeBom Pastor, ser composta quase que totalmente pela classe menos favorecida. Ao mencionar que a prisão não é um fracasso e sim um sucesso diante do que se propõe (controle social), o papel da mesma não é recuperar os seus internos, mas submetê-los às regras impostas pelos grupos sociais, pois segundo Foucault ela contribui para que a lei seja aplicada a um grupo específico. O sistema punitivo seleciona.

Além de terem um grau de escolaridade baixo, essas mulheres reafirmam o retrato da exclusão através de atividades profissionais muito pouco remuneradas. Trabalhos que são consideradas inerentes às mulheres. Atividades que exigem trabalhos do lar. 49\% das mulheres são empregadas domésticas. Quando não se enquadram nessa profissão elas estão em outras que exigem também essas qualidades. A maioria esmagadora trabalha em empregos cuja remuneração é baixa, condizente com o seu nível de escolaridade e sua posição como mulher.

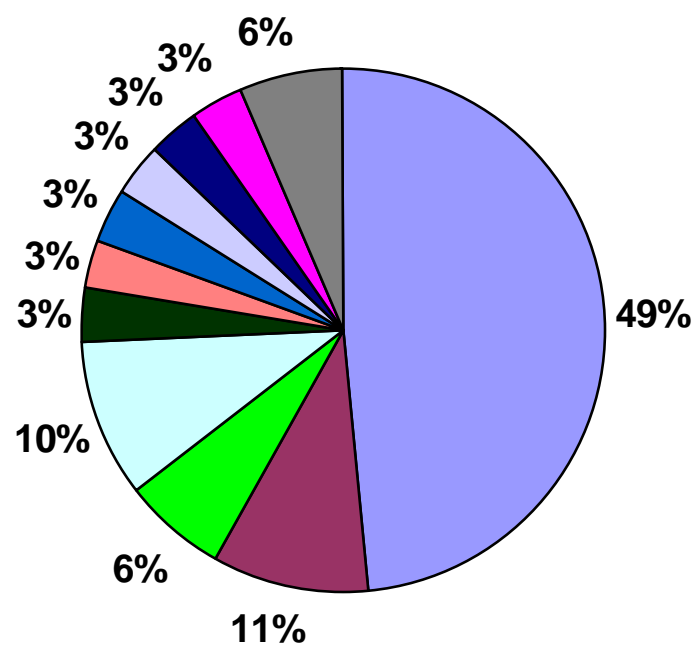

\begin{tabular}{|l|}
\hline$\square$ Doméstica \\
$\square$ Cozinheira \\
$\square$ Ambulante \\
$\square$ Estudante \\
$\square$ Camareira \\
$\square$ Doceira \\
$\square$ Manicure \\
$\square$ Professora \\
$\square$ Comerciante \\
$\square$ Faxineira \\
$\square$ Não Inf
\end{tabular}

Figura 3. Atividade profissional das detentas reincidentes da Colônia Penal do Bom Pastor - PE.

Analisar apenas a questão econômica do nosso sujeito não é suficiente diante desses dados e outros já encontrados em outras pesquisas. Há uma necessidade de estudar a questão de gênero. E quando estamos nos reportando a essa categoria, não estamos nos restringindo ao estudo da mulher, mas a nossa pesquisa irá estudá-la através da mulher. Barbieri conceitua gênero como sendo um conjunto de práticas, símbolos, representações, normas e valores sociais que a 
sociedade elabora a partir da diferença sexual anatômico-fisiológico. E complemente que estudar gênero é ter uma visão mais ampla que permite compreender e explicar o duo "subordinação feminina- dominação masculina."15

Não há que se negar que dentro da história da humanidade papéis masculinos e femininos foram inseridos dentro de uma relação de poder. Mesmo em sociedades pré-históricas, os homens tinham funções diferentes das mulheres, como, por exemplo, caçar, enquanto elas deveriam ficar em casa cuidando dos filhos e dos afazeres domésticos ocasionando uma relação assimétrica entre o homem e a mulher. Essa visão da determinação de papéis é explicada por diversas formas.

Petersen, respaldada nas discussões de Joan Scott, revela que há pelo menos três posições teóricas centrais sobres as relações de gênero: o patriarcado, a tradição marxista e as escolas de psicanálise. Antes de defini-las, é importante deixar claro que todas deram a contribuição no sentido de retirar a determinação dos papéis do âmbito biológico para explicá-los no âmbito social. Por muito se explica uma mulher mais pacata, recuada e tendo que cuidar de afazeres domésticos por sua condição biológica, por ser responsável pela reprodução.

A teoria do patriarcado já começa a defender que a desigualdade entre homens e mulheres é socialmente construída. Esta teoria defende que a dominação masculina teria sua origem no desejo de homens transcenderem a privação dos meios de espécie. Como são as mulheres que podem procriar, por muito elas foram até endeusadas por isso, os homens sentiram a necessidade de dominar as mulheres e controlar a paternidade. Essa teoria continua dizendo que a imposição do poder do pai produziu uma relação assimétrica entre os sexos. Separando-os, colocando-os em estado de guerra e determinando de maniqueísmos. Como o homem sendo o forte, o bom, e a mulher sendo a fraca, a má. ${ }^{16}$

A teoria marxista não se atém apenas a explicações biológicas desse sistema de dominação. Ele a justifica através da necessidade que o sistema capitalista tem de dominar a mulher. $E$ observa que isso se inicia com o surgimento da propriedade privada. A necessidade de demarcar o direito de herança, impôs à

\footnotetext{
${ }^{15}$ BARBIERI, Teresita de. Sobre a categoria gênero: uma introdução teórico-metodológica. Tradução de Antonia Lewinsky. Recife: SOS corpo, setembro de 1993. p. 4.

${ }^{16}$ PETERSEN, Áurea T. Discutindo o uso da categoria gênero e as teorias que respaldam o gênero. IN: Gênero por escrito: saúde, identidade e trabalho. Organizada pro Adriane et alli. Rio Grande do Sul: EDIPUCRS, [S. D.]. p. 16-20.
} 
mulher a monogamia. Dessa forma, seria necessário controlar os passos das mulheres para controle da propriedade privada. Além disso, a mão-de-obra feminina muito interessa. Claus Offe, defende que ela é uma mão-de-obra deslocável para dentro ou para fora do mercado de trabalho, já que possui uma dupla jornada: o trabalho fora de casa e o doméstico. ${ }^{17}$

As teorias psicanalíticas transcendem a explicação do modo-de-produção para discutirem sobre a identidade do sujeito. Segundo Scott, a imposição de normas de interação social é inerente e específica do gênero porque a mulher tem uma relação com o falo diferente do homem. Citando Freud, a autora coloca que tanto a menina quanto o menino tem a mãe com objeto de desejo, mas isso é castrado. Essa interrupção desperta o complexo de Édipo no menino. Já na menina, vai transferir esse amor para o pai e vai se identificar furiosamente com a mãe, que não possui o falo. Segundo a escola francesa, essa realidade trará muitas diferenças na vida de homens e mulheres. ${ }^{18}$

Essa preocupação em explicar a relação desigual entre homens e mulheres revela a importância de decifrar as conseqüências dessas relações em vários ambientes. Não podemos tratar temas como o aqui proposto sem levar em consideração essa relação. Por mais que se diga hoje que a mulher está no mercado de trabalho e que homens e mulheres são iguais, se não analisarmos a questão de gênero, retiramos a complexidade de análises. Primeiro porque já percebemos que o nosso sujeito é pobre e historicamente sempre teve um papel fundamental no sustento do lar pelas próprias condições econômicas. E segundo que, dentro de uma concepção senso comum, é a mulher que na verdade tem um papel do lar. Estudar o gênero não é estudar a mulher, pois ela não existe sem o homem, mas é estudar essa relação. E estamos tentando fazer isso, através das mulheres.

Essa questão de gênero traz uma situação de subordinação de mulheres a dominação masculina. É tanto que para o capital nacional e internacional, essas mulheres subordinadas em função de gênero e classe, constituem uma das mãosde-obra mais baratas e exploráveis do mercado, além de sua capacidade de

17 Apud PETERSEN, Áurea T. Discutindo o uso da categoria gênero e as teorias que respaldam o gênero. IN: Gênero por escrito: saúde, identidade e trabalho. Organizada pro Adriane et alli. Rio Grande do Sul: EDIPUCRS, [S. D.]. p. 26.

${ }^{18}$ Apud PETERSEN, Áurea T. Discutindo o uso da categoria gênero e as teorias que respaldam o gênero. IN: Gênero por escrito: saúde, identidade e trabalho. Organizada pro Adriane et alli. Rio Grande do Sul: EDIPUCRS, [S. D.]. p. 31. 
trabalho, pois elas têm características psicológicas e treinamento desde pequenas a permitir a intensificação dos níveis de exploração: submissão frente a autoridade, disciplina, paciência, para o trabalho tedioso. ${ }^{19}$

Pelas discussões teóricas, observamos que a questão de classe e gênero podem ser motores de opressão. A mulher diante dessas situações de se ver desde pequena dentro de um sistema onde precisa sobreviver, mas tem que se submeter ao poder masculino pode agir de diversas formas. Inclusive, reproduzindo esse sistema. Portanto, a hipótese que estamos levantando é que essa reincidência praticada pelas mulheres é mais uma forma do poder de opressão dos homens. As mulheres nessa situação obedecem ou são levadas pelos seus companheiros para participarem da criminalidade. Essa participação se dá tanto por um problema econômico como de subordinação ao poder masculino. Hipótese que estamos avaliando se será confirmada ou não. Mas que tanto pelo levantamento teórico que fizemos, como de dados já existentes, suscitam a possibilidade de ser uma das causas.

E essa seria a importância dessa pesquisa. Ao se criarem políticas públicas em função desse sujeito, é imprescindível levar em consideração não somente a classe social, mas essa relação de subordinação ao poder masculino. Através das entrevistas é que iremos analisar esses pontos, mas já percebemos em análise de prontuários alguns dados que já direcionam em alguns casos para essa situação. É bom ressaltar que nos prontuários há cópias de partes do processo criminal, onde há o registro da fala das mulheres.

Em alguns deles se coloca que mulheres praticaram crimes em conjunto com homens, foram presas em flagrantes por levarem maconha para o companheiro no presídio masculino(o próprio juiz entendeu, como sendo um daqueles casos em que as esposas levam drogas para os companheiros no presídio.), ou no momento do delito estavam acompanhadas pelo seu companheiro, algumas revelam que foram forçadas pelo marido, matou o ex-companheiro com a ajuda do atual, assaltou um taxista junto com o companheiro. Percebemos em vários casos a presença do homem como centro, auxilio ou mandante das atividades que levam a reincidência criminal.

\footnotetext{
${ }^{19}$ BARBIERI, Teresita de. Sobre a categoria gênero: uma introdução teórico-metodológica. Tradução de Antonia Lewinsky. Recife: SOS corpo, setembro de 1993. p. 12.
} 
Além desses pontos, constatou-se, também, que apesar da grande maioria das mulheres alcançadas pelo estudo possuírem filhos, $90.32 \%$ se dizem solteiras. Iremos averiguar nas entrevistas, qual a concepção que as internas têm disso.



\begin{tabular}{|l|}
\hline$\square$ Solteira \\
$\square$ Amasiada \\
$\square$ Casada \\
$\square$ Viúva \\
$\square$ Não Informado
\end{tabular}

Figura 4- Estado civil das detentas reincidentes da Colônia Penal do Bom Pastor - PE.

\section{CONCLUSÃO}

Aprofundando-se mais na discussão dos possíveis fatores que contribuem para reincidência, percebeu-se a reflexão que as idéias de Foucault causaram. Este autor afirma, de maneira contundente, que a forma-prisão é uma aparelhagem para formar indivíduos dóceis e úteis, através de um trabalho preciso sobre seu corpo. Portanto, a função da prisão não é recuperar os seus internos, mas torná-los dóceis às regras impostas pelos grupos sociais. Esse objetivo é concretizado quando se espalha aos quatro cantos o fracasso da prisão. O fracasso da prisão não erra em seu objetivo, pois ela contribui para que a lei seja aplicada a um grupo específico. ${ }^{20}$

O que o autor pondera, só vem confirmar que o Estado é seletivo em relação aos indivíduos que pune. Afinal de contas, o código penal é infringido a todo o momento por todos os grupos sociais, mas o grupo que está na prisão é o pobre. Foucault defende que a forma de poder moderno é a do poder disciplinar, o Vozes 1987.

${ }^{20}$ Foucault, Michel. Vigiar e punir: Nascimento da prisão; Tradução de Raquel Ramalhete. Petrópolis, 
poder de adestrar através das instituições. ${ }^{21}$ Para este filósofo francês, a prisão está inserida nesse poder disciplinar, ela é apenas uma forma mais grave e radical de implementá-lo.

Shirley Andrade, na conclusão de sua pesquisa - Tempo de prisão é também tempo da cidadania? -, concluiu que o grave problema penitenciário do Brasil não decorre da falta da lei, mas do descumprimento e da desconsideração pelos governantes e autoridades das leis vigentes. ${ }^{22}$

Ainda ao falar do fracasso da prisão, Foucault questiona a utilidade desses diversos fenômenos que a crítica denuncia, o mesmo responde dizendo servir para a delinqüência, indução em reincidência, transformação do infrator ocasional em delinqüente habitual, organização de um meio fechado de delinqüência.

Tais afirmações levam a crer que a reincidência faz parte do sistema penal. Portanto, há vantagens para que ela permaneça. Afinal de contas, como prega Foucault quando a pena de prisão surgiu como conhecemos hoje, ela já tinha o problema da reincidência. Depois de séculos, várias tentativas e legislações que dizem reabilitar o indivíduo para viver socialmente, a reincidência permanece, concluindo-se após o estudo realizado, que o sistema penal é seletivo, pois os números comprovam o retrato do mesmo. As reflexões fornecidas por Foucault já têm alguns anos e a nossa pesquisa confirma mais uma vez que o sistema penal é seletivo.

Todavia, além dessas discussões, levantamos a hipótese que a questão de gênero é um componente importante nas causas da reincidência. Pelas discussões teóricas, observamos que a questão de classe e gênero podem ser motores de opressão, como foi mencionado anteriormente. A mulher diante dessas situações de se ver desde pequena dentro de um sistema onde precisa sobreviver, mas tem que se submeter ao poder masculino, pode agir de diversas formas, inclusive reproduzindo esse sistema. Portanto, a hipótese que estamos levantando é que essa reincidência praticada pelas mulheres é mais uma forma do poder de opressão dos homens. As mulheres nessa situação obedecem ou são levadas pelos seus companheiros para participarem da criminalidade. Essa participação se dá tanto por um problema econômico como de subordinação ao poder masculino. Hipótese que estamos avaliando se será confirmada ou não. Mediante, portanto, levantamento

${ }^{21}$ FOUCAULT, Michel. Vigiar e punir: História da violência das prisões. Tradução de Ligia M. Pondre Vassalo. 12. ed., Petrópolis, vozes, 1987. p. 176. 
teórico que fizemos com dados já existentes, suscitam os mesmos a possibilidade da influência dos companheiros, ser uma das causas da reincidência feminina.

\section{BIBLIOGRAFIA}

ADORNO, Sérgio. Prisão sob a ótica de seus protagonistas.Itinerário de uma pesquisa. Tempo social; Rev. Sociol. USP, S. Paulo, 1991.

ANDRADE, Shirley Silveira. Tempo de prisão é também tempo de cidadania? Programa Institucional de Bolsas de Iniciação científica, CNPq\ UFS. Universidade Federal de Sergipe, Aracaju, 1997.

ANDRADE, Shirley Silveira. Relações de poder: análise essencial para um direito penal democrático. Revista Direitos Humanos, GAJOP, ano 4, n. 8, dezembro 2004. p. 27-34.

BARBIERI, Teresita de. Sobre a categoria gênero: uma introdução teórico-metodológica. Tradução de Antonia Lewinsky. Recife: SOS corpo, setembro de 1993. p. 1-19.

BEAUVOIR, Simone. Mulher independente. In: O segundo sexo: a experiência vivida. Tradução de Sergio Millet. Rio de Janeiro: Nova fronteira, 1980.p.449-485.

BECCARIA, Cesare. Dos delitos e das penas. São Paulo: Martin Claret , 2003.

CRISTIE, Nils. A indústria do controle do crime. Rio de Janeiro: Forense, 1998.

DELMANTO, Celso. Código penal comentado. E ed., Rio de Janeiro: Renovar, 1991.

FOUCAULT, Michel. Vigiar e Punir. Petrópolis: Vozes, 1999.

FOUCAULT, Michel. Microfisica do Poder. Rio De Janeiro: Graal, 1997.

GODINHO, Tatu. O feminismo e a luta dos trabalhadores. Construindo novas relações de gênero. julho, 2003. p.33-38.

HULSMAN, Louk \& CELIS, Jacqueline Bernat de.Penas perdidas: o sistema penal em questão. Rio de Janeiro: Lúmen, 1993.

MINAYO, Mo Cláudia de Souza. Pesquisa Social: teoria, método e criatividade. 10. ed. Petrópolis: Ed. Vozes, 1998.

LIMA, MARIA do socorro de Abreu. Tecendo lutas, abrindo espaços: mulheres nos movimentos sociais dos anos 50. Recife: Editora 8 de março, 2004.

PETERSEN, Áurea T. Discutindo o uso da categoria gênero e as teorias que respaldam o gênero. In: Gênero por escrito: saúde, identidade e trabalho. Organizada por Adriane et alli. Rio Grande do Sul: EDIPUCRS, [S. D.].

VARELLA, Drauzio. Estação Carandiru. São Paulo: Companhia das Letras, 1999.

\footnotetext{
${ }^{22}$ Referência a LEP (Lei de Execuções Penais)
} 